\title{
CAPA Y ESPADA EN LAS FIESTAS MITOLÓGICAS DE CALDERÓN ${ }^{1}$
}

\author{
Santiago Fernández Mosquera \\ Universidad de Santiago de Compostela \\ Facultade de Filoloxía \\ Departamento de Literatura Española, \\ Teoría da Literatura e Lingüística Xeral \\ 15782 Santiago de Compostela \\ Galicia - España \\ santiago.fernandez.mosquera@usc.es
}

[Anuario calderoniano (ISSN: 1888-8046), 6, 2013, pp. 133-147]

La Compañía Nacional de Teatro Clásico ha montado para su Joven Compañía, en el año 2011, la comedia Todo es enredos, Amor de Diego de Figueroa y Córdoba ${ }^{2}$, atribuida a Moreto desde antiguo. Su título evoca directamente, incluso a los que no están obsesionados con las obras de Calderón, el de El mayor encanto, amor, anunciando una relación entre 'encanto' y 'enredo' no difícil de entender.

${ }^{1}$ Este trabajo se inscribe en el Proyecto concedido al Grupo Calderón de la Barca de la Universidade de Santiago de Compostela INCITE09204139PR, Dirección Xeral de $\mathrm{I}+\mathrm{D}$, Xunta de Galicia, del que soy investigador principal, así como en los proyectos DGICYT HUM2007-61419/FILO (IPs. Luis Iglesias Feijoo y Santiago Fernández Mosquera) y en el Proyecto Consolider CSD2009-00033, denominado «Patrimonio Teatral clásico español. Textos e instrumentos de investigación (TC-12)», cuyo coordinador general es el profesor Joan Oleza.

${ }^{2}$ Véase el correspondiente número de Cuadernos Pedagógicos, 36, 2010 publicado por la CNTC. 
De hecho, en la propia comedia así se hace, en los versos finales de la Jornada III ${ }^{3}$ :

\begin{tabular}{|c|c|}
\hline FERNANDO & ¡No me engañé, vive Dios! \\
\hline Manuela & ¿Esto es verdad? \\
\hline Paula & ¿Esto es cierto? \\
\hline DOCTOR & ¡Luego me lo presumí! \\
\hline FÉLIX & ¡Hay tan extraño suceso! \\
\hline FERNANDO & Mujer... \\
\hline MANUELA & Ilusión.. \\
\hline Paula & Enigma... \\
\hline DOCTOR & Encanto... \\
\hline FÉLIX & Prodigio... \\
\hline Elena (Ap.) & ¡Cielos! \\
\hline DOCTOR & $\begin{array}{l}\text { Ya es preciso declararme. } \\
¡ \text { ¡Hay tan extraños enredos! }\end{array}$ \\
\hline
\end{tabular}

'Enredo' y 'encanto' son términos muy cercanos en la intención de aludir al complejo entramado de la acción en las comedias de enredo, de capa y espada, palatinas y añadamos ahora mitológicas, aunque en el caso de 'encanto' sus semas primarios aludan a contextos míticos. Recordemos que este campo semántico es recordado por Elena en la misma comedia cuando exclama ${ }^{4}$ :
[...] que he de usar
cuantos ardides, quimeras, trazas, astucias, engaños, prevenciones y cautelas pueda prevenir la industria (Jornada I)

Todo ello es enredo, y las peripecias de la relación amorosa uno de los más importantes.

El enredo es uno de los elementos esenciales en la delimitación genérica de las comedias y fiestas mitológicas - al menos en bastantes de Calderón-. Dicho enredo se asienta sobre la base temática de los mitos que utiliza, los cuales, como es bien sabido, no carecen de com-

${ }^{3}$ Cito por la suelta de Francisco Suriá, atribuida a Moreto, ejemplar de la Biblioteca de la Universidad de Oviedo.

${ }^{4}$ Recuerda esta cita también Arellano, 1999, p. 67. 
plejas tramas desde su misma constitución. La relación, por lo tanto, entre las comedias mitológicas y las denominadas de enredo nace desde el nacimiento de ambas porque, entre otras cosas, el enredo es consustancial a la comedia, sea esta mitológica o de capa y espada.

Que el enredo es inherente a la comedia es una idea que ya está en los tratadistas del XVII como ha señalado Serralta ${ }^{5}$ quien afirma: «el teatro no puede prescindir de una construcción dramática, o mejor dicho que cualquier teatro es enredo». Entendido así, el concepto de comedia de enredo sería una redundancia, si bien en la gradación y finalidad de dicho enredo estaría su razón de ser:

"comedia de enredo" por antonomasia se podría llamar de momento aquella en la cual, preferentemente bajo la capa de los arreos cotidianos y de los sucesos particulares, se encontraba la mayor concentración de lances y de mecanismos creadores de enredo ${ }^{6}$.

También Felipe B. Pedraza subrayó la relación entre comedia y enredo, vinculándola de manera expresa con la herencia latina, lo cual resulta determinante para asentar el concepto y también para relacionarlo con la carga no trágica que el género mantuvo durante siglos:

El enredo como elemento constitutivo de la acción cómica estuvo siempre presente. Es una herencia de la comedia latina que los poetas españoles de finales del Xvi fijaron como nervio del nuevo teatro popular. Pero su fuerza y predominio sobre otros elementos del drama no fueron constantes ${ }^{7}$.

Ello no quiere decir que no exista enredo en las tragedias, pero su función no es central, sino que es inherente a la generación misma de la trama trágica.

Si hemos establecido una relación inicial y e inmediata entre enredo y comedia mitológica sobre la base general de la trabazón dramática, su vinculación con la comedia de capa y espada es tradicionalmente mucho más directa y ha sido elemento esencial en el

\footnotetext{
5 Serralta, 1988.

${ }^{6}$ Serralta, 1988, p. 129.

7 Pedraza, 1998, p. 8.
} 
establecimiento del género: enredo y capa y espada son conceptos tan cercanos que han llegado a confundirse. Su relación es directa y no es el momento ahora de recordarla.

Más importante será comprobar hasta qué punto las piezas de capa y espada son cercanas a las mitológicas más allá de la base común del enredo. La conexión entre ambas será muy directa si atendemos a los objetivos que señala Arellano para las primeras:

Objetivo final de la comedia de capa y espada me parece ser la construcción de un juego de enredo, muestra del ingenio del dramaturgo, capaz de entretener — suspender- eutrapélicamente al auditorio ${ }^{8}$.

Sin duda, esta finalidad coincidente entre la capa y espada y las mitológicas establece un vínculo directo entre ambos géneros: juego de enredo, profusión de exhibicionismo ingenioso por parte del dramaturgo y gran capacidad de entretener al auditorio, incluso con el añadido de una escenografía espectacular en el caso de las mitológicas.

Al contrario, podríamos pensar que lo que aleja más llamativamente a ambos subgéneros son las coordenadas espacio-temporales, es decir, los «tres tipos de marcas de inserción en la coetaneidad y cercanía al público: geográficas $[\ldots]$, cronológicas $[\ldots]$ y onomásticas $[\ldots] »^{9}$.

En efecto, el diferente protagonismo del espacio, del tiempo histórico y la denominación de los personajes, son en principio las diferencias más llamativas. Sin embargo, el tratamiento de las unidades de espacio y tiempo en lo relativo a su funcionalidad dramática es mucho más cercano de lo que se pudiese pensar, porque poco importa que la acción esté situada en una cueva de Trinacria o en una casa de Toledo si las peripecias y las funciones de esos espacios son muy similares. Lo mismo podríamos decir del tratamiento del tiempo: la idea compartida entre ambos subgéneros es la aparente verosimilitud de los hechos, o en otras palabras, la verosímil inverosimilitud de las de capa y espada que tiene su eco en las piezas mitológicas.

Ya Ignacio Arellano alertó de la falacia de la verosimilitud del uso de las unidades dramáticas en las comedias de capa y espada:

8 Arellano, 1999, pp. 66-67.

9 Arellano, 1999, p. 62. 
Y tal unidad [de tiempo] persigue, a mi juicio, un efecto, contrario al de la preceptiva clasicista, es decir, persigue un efecto de inverosimilitud ingeniosa y sorprendente, capaz de provocar la admiración y suspensión del auditorio. En otras palabras, la unidad de tiempo no puede desligarse de la construcción laberíntica de la trama ingeniosa ni de la acumulación de enredos cuyos efectos potencia ${ }^{10}$.

Este recurso, sin embargo, se distancia en apariencia del uso de las unidades en las comedias mitológicas. Ciertamente, el enredo es común a ambos subgéneros, pero la inverosimilitud espacial y temporal no viene sólo o principalmente por acumulación, sino por extrañamiento. La inverosimilitud está vinculada a los lugares y situaciones exóticos y poco cercanos de la mitología; el tiempo también se abre a nuevas perspectivas no verosímiles, digamos que "novelescas». El poeta no tiene que esforzarse solamente, pues, en maravillar con la acumulación ingeniosa temporal o espacial, sino que el mismo tema mitológico de la comedia le facilita este distanciamiento dramático.

De ahí que la ruptura de la unidad espacial en las comedias mitológicas sí resulte verosímil en términos dramatúrgicos, aunque no temáticos o «realistas»: escenas de monte, volcán, selva, mar, ciudad o palacio se repiten con asiduidad rompiendo la unidad clasicista, pero manteniendo la verosimilitud inverosímil de la comedia nueva en momentos en los que Venus aparece súbitamente en su concha o Júpiter desciende tronante desde los cielos.

Al tiempo, se mantendrá en la comedia mitológica la trama ingeniosa que el enredo provoca, pero relacionado con el entramado de personajes, su acumulación y complejas relaciones. Porque más allá de ellas, la base mitológica ya implica cierto distanciamiento maravilloso, empezando por los nombres de los protagonistas. No obstante, el comportamiento de estos personajes se acerca en más casos a los propios de la comedia nueva que a los seres mitológicos que encarnan. Así sucede de manera explícita con los graciosos, pero también con la mayoría de los restantes que actúan con una lógica de capa y espada o cortesana y no mitológica. Calderón supedita la temática mitológica al desarrollo dramático, y este tiene más que ver con la cotidianeidad de los espectadores y los actores, con la sociedad del XVII, que

${ }^{10}$ Arellano, 1999, p. 45. 
con el comportamiento difuso y arbitrario de los mitos. La construcción del personaje calderoniano en la fiesta mitológica obedece a un desarrollo de comedia, y dentro del género en general, se acerca más al de comedia palatina, palaciega y de capa y espada, entre otras cosas porque la verosimilitud aceptable por un espectador o lector del XVII necesita tener asideros de realidad y el desarrollo de su comportamiento sobre una base lógica aceptada y conocida; y esta base lógica e incluso ideológica tiene que ver en más ocasiones con la capa y espada que con cualquier otro contexto.

El diferente concepto de verosimilitud/inverosimilitud que se manifiesta entre las comedias de capa y espada y las mitológicas mantiene rasgos comunes en la trama, en el enredo. Dice Ignacio Arellano:

La trama de la comedia de capa y espada no obedece a razones de verosimilitud, sino a la técnica del azar controlado por el dramaturgo al libre albedrío de su imaginación y necesidades de enredo ${ }^{11}$.

Lo mismo podría señalarse en las obras mitológicas, con la importante salvedad de que Calderón (y otros autores) debe mantener con la materia mitológica una relación también de "verosimilitud», es decir, de correspondencia temática con los mitos narrados o dramatizados. El «libre albedrío» que explota Calderón en las tramas de capa y espada será menos libre porque obedecerá a la historia dada aunque, como ya se ha señalado, Calderón hace predominar el enredo más ingenioso frente al mito que manipula o modifica según sus intereses dramáticos. Por lo tanto, es la verosimilitud inverosímil del enredo, fácilmente justificable en tramas mitológicas, uno de los rasgos, sino el que más, acerca la comedia de capa y espada y la mitológica.

El factor de alejamiento que supone, en principio, el uso de un espacio y un tiempo tan diferente en ambos géneros, se convierte en un elemento común por cuanto su funcionalidad dramática es idéntica. Su distanciamiento es solo formal y ello se explica porque la base teatral, la comedia nueva y, a mi juicio, la comedia de capa y espada, está detrás del resto del teatro calderoniano.

Así sucede con el concepto de decoro, muy relacionado con la verosimilitud. Dicho decoro está indiscutiblemente unido al género de

11 Arellano, 1999, p. 53. 
la pieza ${ }^{12} \mathrm{y}$, por lo tanto, es susceptible de matizaciones en géneros cercanos, mas no idénticos como el de capa y espada y el mitológico.

Las desviaciones decorosas que podamos encontrar en las comedias mitológicas obedecen siempre a justificaciones mitográficas: los comportamientos amorosos, las muertes, las reacciones extrañas, las rupturas inesperadas de la verosimilitud en las unidades... siempre serán justificadas por su carácter mitológico. Sin embargo, el decoro se mantendrá también justificado cuando sea inverosímil en situaciones de enredo cercanas al género de capa y espada. Lo que señala Arellano para dicho género es perfectamente aplicable a las comedias mitológicas:

La misma mecanización extrema de ciertos recursos (llegada imprevista del padre o hermano que sorprende a los amantes, el esconderse el galán, el trueque de nombre e identidades, los apartes, la confusión provocada por los mantos en las tapadas, los disfraces varoniles, etc.) supone una convencionalización inverosímilmente exagerada ${ }^{13}$.

A estos recursos coincidentes habrían de añadirse otros propios del subgénero mitológico como apariciones y desapariciones súbitas, acciones sobrehumanas, transformaciones en otros seres animados e inanimados... Pero estos elementos inverosímiles dentro del ámbito de la capa y espada serán verosímiles y decorosos en las piezas mitológicas. La verosimilitud y el decoro dependen del género. En este sentido, la inverosímil veracidad de las comedias de santos apuesta por el mismo principio: la subida a los cielos del protagonista de la comedia es verosímil en su contexto de santos como lo es también la conversión de Anajarte en estatua de mármol.

Pero el decoro también se rompe verosímil y tópicamente en las comedias mitológicas por medio de los graciosos. Al igual que en las comedias de capa y espada, los graciosos son los encargados de romper el decoro dramático, de establecer relaciones con los espectadores y lectores y de descontextualizar la acción para reírse de ella o de los personajes. Su función es muy similar, pues, a la capa y espada y a otros géneros de la comedia nueva. Tal vez su protagonismo resulte un

12 Arellano, 1999, p. 52.

13 Arellano, 1999, p. 52. 
tanto diferente por la distancia entre el héroe clásico y su lacayo, ajeno en principio a la tradición mitológica. Es decir, parece menos rupturista que un Chato se ría de un Don Luis que un Pantuflo lo haga de Teseo, un Clarín de Hércules o un Lebrón de Pigmalión. También en esto se produce un proceso de acercamiento en las relaciones entre los personajes de los distintos géneros: héroes mitológicos que se comportan como caballeros y graciosos que se ríen de ellos por ser héroes. Por lo tanto, la aparente diferencia entre los personajes es, como ya se ha dicho arriba, más onomástica que de construcción del personaje dramático.

Para ejemplificar lo señalado hasta aquí pongamos un ejemplo diferente a las primeras fiestas mitológicas ya analizadas en otras ocasiones y acudamos a una comedia mitológica central en la obra de Calderón, La fiera, el rayo y la piedra. La obra es representativa del género ${ }^{14}$, pero sobre todo es un precioso ejemplo de lo que hemos intentado explicar hasta aquí: su relación con la capa y espada. Así lo entiende su primera editora moderna Aurora Egido ${ }^{15}$ :

La obra se estructura dentro de los convencionalismos genéricos de la época, presentando unos personajes que por su número generan toda clase de entrecruzamientos, suspenses y equívocos como en comedia de enredo. [...] Los argumentos mitológicos quedan supeditados a la invención calderoniana de los asuntos a los que sirven.

${ }^{14} \mathrm{Si}$ aplicamos la caracterización realizada por Fausta Antonucci, 2005, p. 14, en su introducción a la comedia de capa y espada por excelencia, La dama duende, las coincidencias aún pueden resultar más significativas: «las comedias de capa y espada [...] responden todas, en su estructura, a un mismo patrón. Protagonizan la intriga dos parejas, cuyo amor se ve obstaculizado de muy diversas formas por los celos y/o por la oposición de una figura que encarna la autoridad paternal (el padre o el hermano); suele haber a menudo un tercer galán, cuyas esperanzas amorosas quedan frustradas al final de la comedia. En el número de los personajes entran también criados y criadas, cuyas actuaciones y comentarios funcionan esencialmente como contrapunto a la manera de razonar y de actuar de sus amos. La intriga tiende a complicarse en la parte final de los actos primero y segundo, especialmente por equívocos y malentendidos, en cuyo juego desempeña un papel importante — sobre todo a partir de los años veinte del siglo- el espacio doméstico con sus trampas, escondrijos, sótanos, salidas dobles, puertas ocultas...». Aunque no profundicemos ahora en ello, por ejemplo, la presencia de Ifis como galán que no logra matrimonio es un claro ejemplo del galán suelto característico de la capa y espada.

15 Egido, 1989, p. 65. 
En esta contextualización general de la obra, Aurora Egido ${ }^{16}$ la vincula directamente con el género de capa y espada:

La obra muestra un alto grado de mecanización en todos sus niveles. Dejando aparte el estilo, hay parejas cruzadas, equívocos, escondites, disfraces, identidades ocultas, secuestros, guerras, confusiones, errores, casualidades, equívocos y enredos propios de la comedia y aquí multiplicados. [...] Calderón ofrece en esta obra numerosas analogías con otras comedias mitológicas, pero también con las comedias de honor, de capa y espada, de enredo, etc., señalando hasta qué punto el convencionalismo del género está por encima de la materia mitológica.

Para ilustrar esta relación a través del gracioso, qué mejor que elegir el elemento anecdóticamente más significativo del género capa y espada como son las espadas y su uso, es decir, los duelos. En $\mathrm{La}$ fiera... ${ }^{17}$ existen varios, algunos en clave casi cortesana, de finezas entre rivales como el de Ifis y Céfiro (vv. 934 y ss., pp. 1089 y ss., «Yo te doy deso palabra...»), que derivará en otro físico con lucha entre Céfiro y Anteo, y que aparecerá, de nuevo, al final de la segunda jornada en el enfrentamiento entre Ifis y Céfiro (vv. 2468 y ss., p. 1147):

ANAJARTE

IFIS

IRÍFILE

IFIS

CÉFIro
¿A defender y ofender

a un mismo tiempo venís?

¿De dónde o cómo, en mi ofensa

y en mi defensa, salís?

Después lo sabrás, que agora

dar muerte a ese mostruo vil

sólo me toca.

\begin{tabular}{l}
\multicolumn{2}{c}{ Primero } \\
me darás la muerte a mí. \\
Sí haré; que por Anajarte \\
en nada debo advertir.
\end{tabular}

No harás; que aunque más me importe

a mí su muerte que a ti,

Irífile le defiende,

y por ella ha de vivir.

16 Egido, 1989, pp. 69-70.

17 Cito el texto por la edición de Cruickshank, 2007. 
IFIS

Eso es volver nuestro duelo

a aquella primera lid.

CÉfIRO Pues ¿a qué mejor principio que al de matar o morir?

Pigmaleón Eso no; que estoy yo en medio, que a los dos debo asistir.

Anajarte Ninguno saque la espada; que acción es más varonil tal vez, en quien reñir sabe, reportarse que reñir; que yo, porque no volvamos hoy, en repetida lid, a aquello de "a mí me toca rendirla, y librarla a mí», quiero sacar este empeño de sus quicios, y acudir a ver si yo elijo medio que a todos componga.

Sin embargo, el duelo más significativo es aquel de procedencia directa del género "capa y espada» (vv. 1778 y ss., p. 1125). Véase el claro ejemplo el envalentonamiento poco resolutivo de algunos personajes
CÉFIRO
A eso no me toca a mí responder, sino a mi acero.
Pigmaleón
Mirad, tened...
de cuya actitud se burla el gracioso Lebrón
LEBrón Pues vaya de cumplimiento, y nadie tire a matar, pues bastará, como diestros, el señalar las heridas.

para más adelante rematar con la explicación (pp. 1127-1128)

ANAJARTE

LEBRÓN
¿Nadie me dice qué es esto?

Yo, señora, lo diré.

Esto es que tres majaderos, 
sobre quién se ha de matar, se hacen dos mil cumplimientos. «Mate usted.» - «No, sino usted.» — «Usté ha de matar primero.» $\mathrm{Y}$ tras esto, viven todos.

El contexto de la burla de Lebrón remite directamente al género de capa y espada cuando el personaje se ríe de la falsa heroicidad de estos caballeros de espada fácil y actitud valentona. Y estas escenas, si las leemos descontextualizadas, se integrarían mejor en un ámbito urbano e hidalgo que caballeresco o mitológico.

En general, la actitud antiheroica de algunos graciosos parece encajar más en el género de capa y espada. Así sucede con Lebrón en La fiera... en especial cuando se burla del desatino del su amo Pigmalión enamorado de una estatua. La burla de Lebrón procede del ámbito popular y no del mitológico ni cortesano.Véase, si no, la valoración irónicamente positiva de una mujer estatua (vv. 2192 y ss., pp. 1138-1139):

LEBRÓN

Porque quien no sabe hablar, no sabrá pedir. ¿Hay cosa más descansada que amanecer uno sin cuidar de lo que su dama ha de comer y vestir? Y más en tiempo que el traje está tal que, sin mentir, no se usa por mayo el jubón que se hizo en abril. Fuera de que, ¿qué reposo puede haber como dormir seguro de que su dama en casa está, y siendo así que es corriente, saber que no se ha de mudar? Y, en fin, sólo hay malo, a mi ver,...

Pigmaleón ¿Qué?

LEBRÓN ... que es materia muy civil mármol, y había de ser bronce 
para haberte de sufrir.

La cotidianeidad a la que remite la burla de Lebrón no encaja en el contexto mitológico. Sus referentes son contemporáneos para quien escucha y para quien representa y no aquilatados al ambiente ahistórico de la situación mitológica. El humor, de hecho, será más efectivo si se agarra a lo cotidiano tanto de quien vive situaciones similares como de quien las disfruta en cabeza (de mujer, habríamos de decir aquí) ajena.

El gracioso de las fiestas mitológicas, por otro lado, cobra una importancia estructural tal vez mayor que en el género de capa y espada porque suele ser un añadido a la trama mitológica y dirige la comedia hacia una interpretación no grave, no trágica, sino festiva, como he intentado demostrar para El mayor encanto, amor y para Los tres mayores prodigios. El peso de los graciosos es tal en estas obras que impiden la consideración de estas fiestas mitológicas como obras trágicas. Y también en este sentido nos encontramos ante un género paralelo al de capa y espada en donde las interpretaciones trágicas que se han generado a partir de ciertas lecturas modernas no se corresponden con el sentido final, ya sea contextualizado en la representación del momento histórico, ya sea en la interpretación actual: si las comedias de capa y espada son puro divertimento, también las comedias mitológicas son pura diversión y fiesta más o menos sofisticada.

Así como Arellano y Luis Iglesias Feijoo ${ }^{18}$ entre otros han demostrado que las comedias de capa y espada no deben ser interpretadas en clave trágica, así también las comedias mitológicas calderonianas no pueden entenderse trágicamente; o, dicho de otra manera, la mayoría de las comedias mitológicas están compuestas en clave de comedia y los hechos aparentemente trágicos que dramatizan se entienden dentro del decoro de la diversión, lo que no implica la carencia de reflexiones sobre los asuntos más variopintos y serios del ser humano. Pero no son equivalentes a las tragedias calderonianas como El mayor monstruo del mundo o A secreto agravio. Lo he intentado demostrar en los trabajos centrados en la fiesta mitológica Los tres mayores

18 Lo han explicado magníficamente Luis Iglesias Feijoo, 1998, e Ignacio Arellano, 1990; 1999; 2006, pp. 155 y ss. 
prodigios la cual, paralelamente a la interpretación trágica de comedias de capa y espada, fue entendida como tragedia.

Sin embargo, la comedia mitológica tiene una fácil derivación de recepción moralizadora ya implícita en los temas mitológicos que aborda, algo no presente de manera explícita en la comedia de capa y espada, pero que también reconoce Arellano ${ }^{19}$ :

Se trata, pues, creo, de un universo fundamentalmente lúdico, no trágico. Sin duda pueden hallarse implicaciones serias (buscadas o no por el dramaturgo), sobre todo en el terreno de ciertos problemas sociales (relaciones entre sexo y generaciones, opresión de ciertos sistemas de valores...) morales (el problema de la responsabilidad, por ejemplo), pero, a mi juicio, la actitud que debió dominar (y sigue dominando, supongo) en la recepción áurea de la comedia de capa y espada, es la que se rastrea en un texto de Cubillo de Aragón, de El enano de las Musas, donde se burla del que

va a la comedia muy preciado

de oir cosas de seso,

que el tablado no se hizo para eso.

la comedia búscala graciosa,

entretenida, alegre, caprichosa...

Si es cierto que la tradición hermenéutica mitográfica favorece la interpretación moralizadora, tampoco se podrá negar que la cercanía espacio-temporal puede hacer más significativas y socialmente más perturbadoras estas reflexiones moralizantes de la capa y espada, mientras que el distanciamiento mitológico, general y ahistórico, confinaría estas enseñanzas al campo más teórico y menos atendible en la práctica. En otras palabras, un espectador del XVII (y de todas las épocas) tal vez se vea más cercano a Don Juan que a Ulises y entienda que las lecciones que recibe el primero son más atendibles que las heroicas peripecias del segundo.Y, además, dichos valores serios en muchas ocasiones se verán subordinados al peso del mero disfrute dramático, visual, espectacular y musical de la pieza, circunstancia que no se producirá en la comedia de capa y espada.

${ }^{19}$ Arellano, 1999, pp. 67-68. 
La directa relación entre ambos géneros que he intentado demostrar en estas páginas se produce porque la comedia mitológica tiene que apoyarse en muchos casos en elementos propios de las de capa y espada porque son éstas las que aportan ritmo, verosimilitud, cercanía al espectador (incluso al cortesano) y son las fundadoras de un nuevo teatro que aparece como una superestructura que engloba también a la tragedia o al auto sacramental, por citar otros géneros. La comedia de capa y espada educó al espectador y también al dramaturgo, creó la modernidad teatral basada en la comedia nueva: sin capa y espada la fiesta mitológica no sería como hoy se conserva ni habría tenido el éxito que tuvo en su momento.

Pudiera resultar llamativo que fiestas cortesanas de base mitológica y/o novelesca hubieran de componerse o representarse incluso antes de las que hoy conocemos como capa y espada, como así nos consta con la anónima Fábula de Dafne $e^{20}$, y sin embargo con menos éxito que el obtenido por Calderón en la segunda mitad del XVII con sus obras mitológicas. Esto es debido a que la aportación del género capa y espada, totalmente consolidado en Calderón y aceptado por el público del XVII, preparó la recepción de las fiestas mitológicas y contribuyó definitivamente a su éxito a lo largo de todo el siglo.

${ }^{20}$ Puede consultarse, entre otros, el capítulo «La tradición mitológica cortesana: la anónima Fábula de Dafne, Adonis y Venus y La Fábula de Perseo de Lope», del ya clásico trabajo de Teresa Ferrer, 1991, pp. 144 y ss. 


\section{Bibliografía}

Arellano, I., «Metodología y recepción: lecturas trágicas de comedias cómicas del Siglo de Oro», Criticón, 50, 1990, pp. 7-21.

- Convención y recepción. Estudios sobre el teatro del Siglo de Oro, Madrid, Gredos, 1999.

- El escenario cósmico. Estudios sobre la Comedia de Calderón, Madrid / Frankfurt, Iberoamericana / Vervuert, 2006.

Calderón de la Barca, P., La dama duende, ed. F. Antonucci, Barcelona, Crítica, 2005.

- La fiera, el rayo y la piedra, ed. A. Egido, Madrid, Cátedra, 1989.

- La fiera, el rayo y la piedra, Tercera Parte de comedias, ed. de Don W. Cruickshank, Madrid, Biblioteca Castro, 2007.

Cuadernos pedagógicos, núm. 36, Todo es enredos, Amor de Diego de Figueroa y Córdoba, Madrid, INAEM, 2010.

Fernández Mosquera, S., «La violencia textual en Calderón. Rastros de sangre en la fiesta Los tres mayores prodigios», en prensa.

- «Las comedias mitológicas de Calderón: entre la fiesta y la tragedia. El caso de Los tres mayores prodigios», en Hacia la tragedia áurea. Lecturas para un nuevo milenio, ed. F. A. de Armas, L. García Lorenzo, E. García SantoTomás, Madrid / Frankfurt, Iberoamericana / Vervuert, 2008, pp. 153179.

- «Los tres mayores prodigios de Calderón: una fiesta no trágica», en prensa.

Ferrer Valls, T., La práctica escénica cortesana: de la época del emperador a la de Felipe III, London, Tamesis, 1991.

Iglesias Feijoo, L., "QQue hay mujeres tramoyeras": La "matemática perfecta" de la comedia calderoniana", en La comedia de enredo. Actas de las XX Jornadas de Teatro Clásico, Almagro, 1997, ed. F. B. Pedraza Jiménez y R. González Cañal, Almagro, Festival de Almagro / Universidad de CastillaLa Mancha, 1998, pp. 201-236.

La comedia de enredo. Actas de las XX Jornadas de Teatro Clásico, Almagro, 1997, ed. F. B. Pedraza Jiménez y R. González Cañal, Almagro, Festival de Almagro / Universidad de Castilla-La Mancha, 1998.

Serralta, F., «El enredo y la comedia: deslinde preliminar», Criticón, 42, 1988, pp. 125-135.

Todo es enredos amor, y diablos son las mujeres, de don Agustín Moreto, suelta núm. 233, Barcelona, por Francisco Suriá y Burgada, Impresor. Cito por el ejemplar de la Biblioteca Universitaria de Oviedo. 